\title{
Endoscopic mucosal resection with circumferential incision for treatment of rectal carcinoid tumours
}

\author{
Jin Huang ${ }^{1}$, Zhong-Sheng Lu $^{2}$, Yun-sheng Yang ${ }^{2 *}$, Jing Yuan ${ }^{3}$, Xiang-dong Wang ${ }^{4}$, Jiang-yun Meng ${ }^{4}$,
} Hong $\mathrm{Du}^{4}$ and Hong-bin Wang ${ }^{4}$

\begin{abstract}
Background: Endoscopic mucosal resection (EMR) is simple and quick and has low complication rates. However, the disadvantage of local recurrence or remnant rate limits the use of this technique. We aimed to analyse the outcomes of conventional EMR and EMR with circumferential incision (CIEMR), a simplified modification of EMR, in the endoscopic treatment of rectal carcinoid tumours.

Methods: A total of 59 consecutive patients with rectal carcinoid tumours without regional lymph node enlargement confirmed by endoscopic ultrasonography were included in the study. These patients underwent endoscopic treatment from January 2009 to September 2011 and were randomly designated into CIEMR $(n=31)$ or EMR group $(n=28)$. En bloc resection rate, pathological complete resection rate, procedure time, complications and follow-up outcomes were analysed.

Results: The en bloc resection rate was not significantly different between the CIEMR and EMR groups (100\% versus $96.55 \%, P>0.05)$. The pathological complete resection rate was higher in the CIEMR group than in the EMR group (96.7\% versus $82.14 \%, P<0.05)$. The overall complication rate, delayed bleeding and procedure time were not significantly different between the two groups. No recurrence was observed in either the EMR or CIEMR group.

Conclusions: CIEMR optimises the procedure of EMR and simplifies the technique of endoscopic submucosal dissection; thus, it has a better histologically complete resection rate and more acceptable complication rate than EMR. Thus, CIEMR may be preferable to conventional EMR for resection of rectal carcinoid tumours less than $15 \mathrm{~mm}$.
\end{abstract}

Keywords: CIEMR, Endoscopic mucosal resection (EMR), Rectal carcinoid tumours

\section{Background}

Carcinoid tumour is a slow-growing type of neuro-endocrine tumour that originates in the cells of the neuroendocrine system [1]. Over two-thirds of carcinoid tumours are found in the gastrointestinal tract [2]. Rectal carcinoid tumours are uncommon, representing $1.1 \%$ to $1.3 \%$ of all rectal neoplasms $[3,4]$. Most rectal carcinoid tumours are asymptomatic and found during screening colonoscopy. The surgical treatment for carcinoid tumours is generally dictated to a degree, but not absolutely, by size [5]. Tumours less than $1 \mathrm{~cm}$ in diameter are rarely associated with metastatic disease. Tumours measuring from $1.0 \mathrm{~cm}$ to $1.9 \mathrm{~cm}$ in diameter tend to show a metastatic rate of $4 \%$

\footnotetext{
* Correspondence: yunshengyangcn@163.com

${ }^{2}$ Department of Gastroenterology, Chinese PLA General Hospital, 28 Fuxing Road, Beijing 100853, China

Full list of author information is available at the end of the article
}

to $30 \%$ [6,7]. Lymph node or liver metastases are observed in over $80 \%$ of tumours measuring more than $2 \mathrm{~cm}$ in diameter. Therefore, small rectal carcinoid tumours are usually managed with local excision including endoscopic techniques $[8,9]$.

Endoscopic mucosal resection (EMR) is generally performed for gastrointestinal lesions because of its simplicity, quick operation and low complication rates [10-13]. However, locally recurrent or remnant tumours after EMR of gastrointestinal tumours have been increasingly reported $[14,15]$, coinciding with increased use of EMR. EMR could be used to complete resection of mucosal lesions less than $2 \mathrm{~cm}$, and rectal carcinoid tumours suitable for endoscopic treatment are generally less than $2 \mathrm{~cm}$, but lateral and vertical margin involvement has recently been reported [16]. Endoscopic submucosal dissection (ESD) is a therapeutic technique used to treat gastrointestinal neoplasms with a 
high en bloc resection rate. However, ESD is not widely used to treat rectal carcinoid tumours in China because of its technical difficulty, longer procedure time and increased risk of perforation. Circumferential incision is one of the procedures of ESD. Hirao et al. [17] first reported EMR with circumferential incision (CIEMR) in 1986. The application of CIEMR in early gastric cancer has been previously reported $[18,19]$. CIEMR reduced the operative time and avoided the risk of perforation for lesions less than $2 \mathrm{~cm}$.

The present study compared CIEMR with EMR for the treatment of rectal carcinoid tumours. En bloc resection rate, histological complete resection rate, complications, resection time and follow-up outcomes were measured to determine an effective and simple treatment approach for rectal carcinoid tumours. The aim of this study was to assess the outcomes of conventional EMR and CIEMR in the endoscopic treatment of rectal carcinoid tumours.

\section{Methods \\ Patients}

Conventional EMR and CIEMR were performed on 59 lesions in 59 patients with rectal carcinoid tumours. These treatments were carried out at the Chinese PLA General Hospital, Beijing, China between January 2009 and September 2011. The patients were randomly divided into CIEMR $(n=31)$ or EMR groups $(n=28)$. All patients were asymptomatic, and all tumours were found incidentally on screening colonoscopy. The inclusion criterion was patients with rectal carcinoid tumours less than $15 \mathrm{~mm}$ without significant evidence of regional lymph node enlargement on computer tomography (CT) scanning or endoscopic ultrasonography (EUS). All lesions were diagnosed by EUS as tumours in the submucous layer and confirmed by histological evaluation of endoscopic biopsy specimens before EMR/CIEMR. Rectal carcinoid tumours with distant metastases to the liver or lung on CT scans were excluded. Two experienced endoscopists (LZS and HJ) performed all EMR/CIEMR procedures. Informed consent was obtained from each patient. All aspects of this study were approved by the medical ethical committee of the Chinese PLA General Hospital.

The endpoint of the present study was the differences of clinical efficacy between CIEMR and EMR, the variables evaluated included en bloc resection rate and pathological complete resection rate, as well as procedure time, complications and follow-up outcomes.

\section{CIEMR and conventional EMR procedures}

A single-accessory channel endoscope (GIF-Q260J; Olympus, Tokyo, Japan) was used during the procedure. A short transparent cap was attached to the tip of the endoscope (ND-201-11802, Olympus, Tokyo, Japan).
An electrosurgical current generator (VIO200, ERBE, Tubingen, Germany) was used for endoscopic treatment.

CIEMR was performed as follows (Figure 1): 1) marking dots were made approximately $2 \mathrm{~mm}$ to $3 \mathrm{~mm}$ outside the lesion with a dual knife (KD-650Q, Olympus, Tokyo, Japan); 2) a solution (250 mL fructose-glycerol (Chia Tai Fenghai Pharmaceutical Co., JS, China) $+1 \mathrm{~mL}$ epinephrine $+0.3 \mathrm{~mL}$ methylthioninium chloride) was submucosally injected around the lesion using a needle (INJ1-A1-07-5-23-180, Medwork, Neuss, Germany). After the injection, only the mucosa was lifted off the muscularis propria layer; 3 ) then, the mucosa was incised outside the marker dots using a dual knife; 4) the tumour was resected with a snare. The visibly exposed vessels on the artificial ulcer were coagulated with a Coagrasper (FD-410LR, Olympus, Tokyo, Japan) or argon plasma coagulation to prevent delayed bleeding. CIEMR resection time was counted from the time of making the marking dots to the completion of resection.

Conventional EMR procedure in this study was performed by ER-cap technique. An ER kit (Olympus, Tokyo, Japan) was used, which contains a spraying catheter, an injection needle, a hard oblique cap (inner $12 \mathrm{~mm}$ ) and a crescent-shaped snare. The cap was attached to the tip of the endoscope, and the endoscope was reintroduced. The lesion was initially lifted by submucosal injection. Then, the snare was prelooped in the distal rim of the cap, and the mucosa was sucked into the cap before the snare was tightened. Resection time of conventional EMR was defined as the time from the submucosal injection to the completion of resection.

\section{Histopathological evaluation}

Specimens were microscopically examined for histopathological type, invasion depth, lateral and vertical resection margins and lymphovascular involvement. En bloc resection referred to resection of the entire tumour in one piece rather than piecemeal. The histopathologic evaluation of gastrointestinal neuro-endocrine neoplasm in this study was NET - G1 according to the World Health Organization (WHO) 2010 classification of tumors of the digestive system.

A pathological complete resection was defined as an en bloc resection with no lateral and vertical margin involvement of the resected specimen and no lymphovascular invasion.

\section{Follow-up}

The patients were followed-up by colonoscopy at 3, 6 and 12 months and then annually thereafter. The patients with vertical or lateral resection margin involvement were recommended for additional surgery and followed-up with chest radiography and abdominal-pelvic CT scanning. 


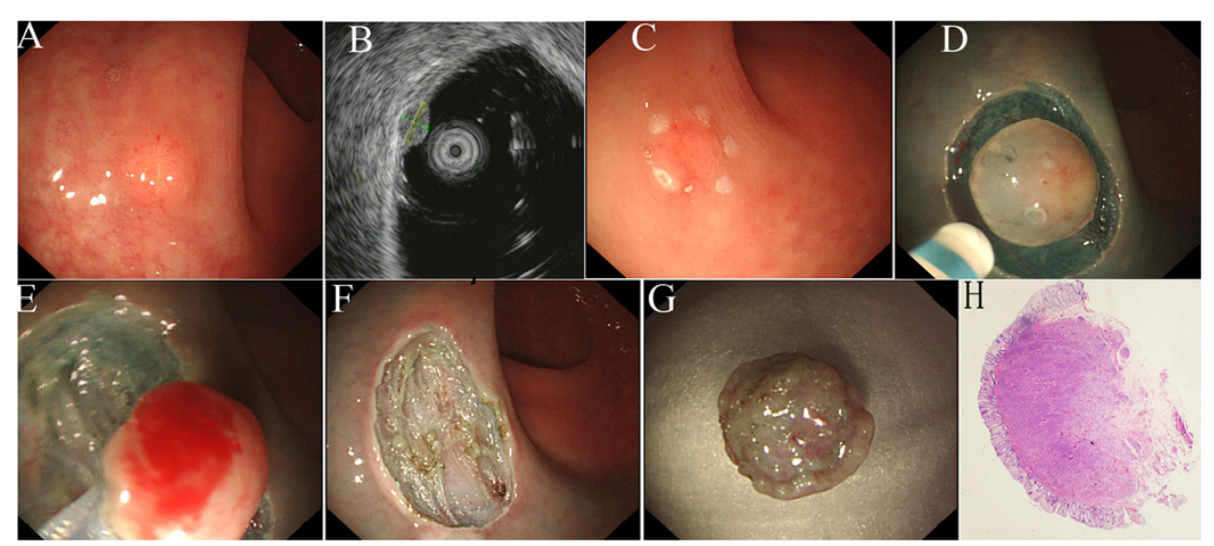

Figure 1 Endoscopic mucosal resection with circumferential incision of a rectal carcinoid tumour. (A) Conventional endoscopic view showing a carcinoid tumour in the rectum; (B) Endoscopic ultrasonography (EUS) image showing the lesion not to invade the muscularis propria layer; (C) Marking dots made around the lesion; (D) Circumferential incision around the dots; (E) Snaring after circumferential incision; (F) Region after endoscopic mucosal resection with circumferential incision; (G) Resected specimen; (H) Histologic view of a rectal carcinoid tumor obtained by endoscopic submucosal dissection (ESD) (H\&E stain; ×40).

\section{Statistical analyses}

Statistical analysis was performed by using SPSS software (version 12.0; SPSS Inc, Chicago, IL, USA). Significant difference between the two groups was analyzed using Fisher exact test and Mann-Whitney $U$-test. $P<0.05$ was considered significant for two-tailed tests.

\section{Results}

\section{Characteristics of patients and tumours}

Sex and age distribution were similar in conventional EMR and CIEMR groups (31 CIEMR and 28 EMR). The endoscopically estimated diameter of rectal carcinoid tumours was $3 \mathrm{~mm}$ to $15 \mathrm{~mm}$ in both groups. The histologically measured sizes of the resected specimens were similar to the endoscopically estimated diameters. Table 1 shows the characteristics of the two groups.

\section{Outcomes of CIEMR/EMR}

The clinical outcomes of the CIEMR and EMR groups are shown in Table 2. The en bloc resection rate was not

Table 1 Characteristics of patients and tumours

\begin{tabular}{llll}
\hline & CIEMR & EMR & P-value \\
\hline Age, mean \pm SD, years & $50 \pm 10.1$ & $49 \pm 12.2$ & 0.62 \\
Sex, $(\mathrm{n} \%)$ & & & 0.75 \\
Male & 17 & 15 & \\
Female & 14 & 13 & \\
Tumor size $(\mathrm{mm})^{\text {a }}$ & & & 0.73 \\
Mean \pm SD & $9 \pm 2.5$ & $8 \pm 3.3$ & \\
Range & 3 to 15 & 3 to 15 & \\
Distance from the anal verge $(\mathrm{cm})$ & $6.1 \pm 2.5$ & $6.2 \pm 3.0$ & 0.67
\end{tabular}

CIEMR, conventional endoscopic mucosal resection with circumferential incision.

EMR, endoscopic mucosal resection.

${ }^{\text {a }}$ Tumour size was determined by pathological findings. significantly different between the two groups $(P>0.05)$ (Figure 2). The pathological complete resection rate was higher in the CIEMR group than in the EMR group $(P<0.05)$. Lateral resection margin involvement was observed in three cases (10.3\%) in the EMR group but not in the CIEMR group. Vertical resection margin involvement was observed in two cases (6.9\%) in the EMR group versus one in the CIEMR group (3.3\%). No lymphovascular invasion occurred in either the CIEMR or EMR group. The median CIEMR operative time and EMR operative time were 7.6 minutes (range, 5 minutes to 13 minutes) and 4.2 minutes (range, 2 minutes to 10 minutes), respectively.

\section{Complications}

No perforations or delayed bleeding occurred in any xpatient of both groups. Procedure-related bleeding occurred in all CIEMR cases and in 21 of 28 of EMR cases, but haemostasis was achieved by endoscopic treatment. None of the patients required blood transfusion.

Table 2 Clinical outcomes of circumferential incision endoscopic mucosal resection (CIEMR) and endoscopic mucosal resection (EMR)

\begin{tabular}{llll}
\hline & CIEMR & EMR & $P$-value \\
\hline En bloc resection, n (\%) & 100 & 96.55 & 0.747 \\
Pathologic complete resection, n (\%) & 96.7 & 82.14 & 0.043 \\
Resection time (minutes) & 7.6 & 4.2 & 0.028 \\
Complication, n (\%) & & & \\
Delayed bleeding & 0 & 0 & 1 \\
Perforation & 0 & 0 & 1 \\
Follow-up & $19.1(8.6)$ & $18.3(7.9)$ & 0.588 \\
\hline
\end{tabular}

CIEMR, endoscopic mucosal resection with circumferential incision. EMR, endoscopic mucosal resection. 


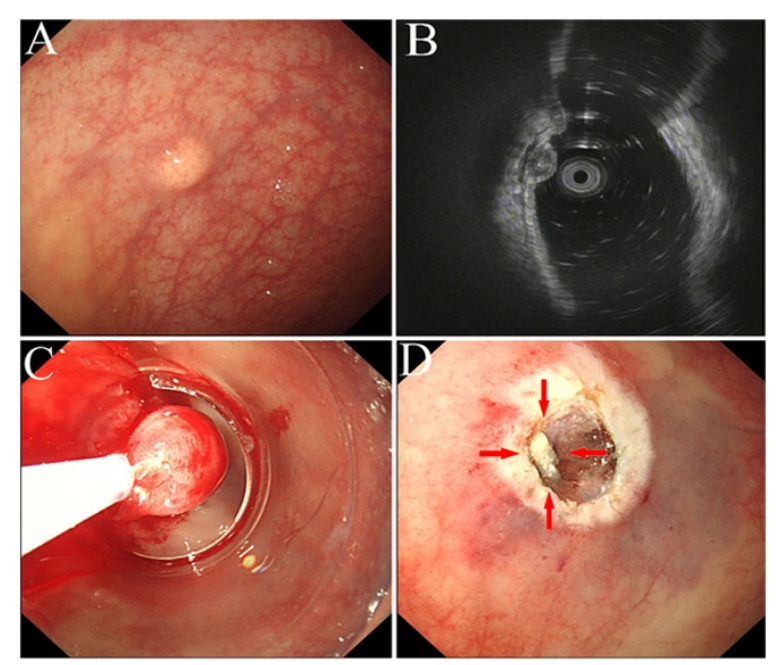

Figure 2 Incomplete resection using endoscopic mucosal resection (EMR). (A) Conventional endoscopic view showing a carcinoid tumour in the rectum; (B) Endoscopic ultrasonography (EUS) image showing the lesion in the muscularis propria layer; (C) Snaring after submucosal injection; (D) Remnant carcinoid tumour on post-EMR ulcer (red arrow)

The complication rates did not significantly differ between the EMR and CIEMR groups $(P=1.00)$.

\section{Follow-up outcomes}

No local recurrence occurred during a median follow-up period of 20 months (range, 3 months to 35 months) in patients with pathological complete resection in both the CIEMR and EMR groups. An incomplete pathological resection was found in five patients of the EMR group. Six patients with vertical and lateral resection margin involvement were converted to open surgery. Postoperative pathological diagnosis was positive for carcinoid in two patients in the EMR groups. No local remnant lesion was observed during the median follow-up period of 17 months (range, 3 months to 30 months).

\section{Discussion}

EMR is a safe and useful endoscopic strategy for small and superficial neoplasms confined to the mucosa or superficial submucosa in the colorectum. However, the high recurrence rate of residual lesions is a restrictive factor for EMR application. ESD, devoid of the disadvantages of EMR, is performed to locally treat small rectal carcinoid tumours to achieve complete resection rates, but the entire ESD is difficult and the complication rate is high. This study performed CIEMR in rectal carcinoid tumours and compared the clinical outcomes between CIEMR and EMR.

Patients with rectal carcinoid tumours not larger than $15 \mathrm{~mm}$ were chosen in this study. Given that most rectal carcinoid tumours that we detected were small, the result agreed well with that reported in the literature [20]. Metastasis is reported to occur in $5 \%$ to $15 \%$ of carcinoid tumours measuring $10 \mathrm{~mm}$ to $19 \mathrm{~mm}$, and the frequency increases to over $80 \%$ for tumours sized $20 \mathrm{~mm}$ or larger [21]. ESD was performed in patients with rectal carcinoid tumours larger than $15 \mathrm{~mm}$ in our hospital. The en bloc resection rate was not significantly different between the CIEMR group and the EMR group because the lesion size was small. CIEMR is a modification on EMR that involves the circumferential incision procedure of ESD to ensure a safe margin. Lateral resection margin involvement was observed in three cases in the EMR group versus none in the CIEMR group. Although the procedure time of CIEMR seemed significantly longer than that of EMR (7.6 minutes versus 4.2 minutes) because of marking, circumferential resection and other extra steps, the mean resection time (7.6 minutes) was acceptable. In this study, the complication rate in the CIEMR group was similar to that in the EMR group. No perforation occurred in either group, probably because the lesions were small. Intraoperative bleeding was successfully managed by endoscopic treatment, and no delayed bleeding occurred.

Compared with conventional EMR, the advantage of CIEMR is risk reduction of residual tumours because the side margin of the lesion is clearly exposed after circumferential incision. Given that residual or recurrent tumours usually develop from remnant tumour tissues from the resected margin, determining the lateral margin blindly and confirming the presence or absence of any residual tumour after resection because of ablation are difficult for conventional EMR. After circumferential incision, the snare can be easily placed along the incision, and the tumour margin can be reliably cut. But the disadvantage of CIEMR is the longer procedure time versus EMR. Compared with ESD, CIEMR procedure is easier because submucosal dissection, one of the most difficult ESD procedures, is omitted. Snaring becomes simple and safe after circumferential incision. And the procedure time of CIEMR is shortened and the risk of complications such as perforation is reduced.

The first limitation of this study is the single-centre design. More experience from other centres is necessary to define the indication for CIEMR. Second, CIEMR or EMR was only performed in rectal carcinoid tumours. Considering that the rectum is wide and fixed and has fewer mucosal folds, endoscopic manoeuvrability in the rectal area is usually better than that in other locations of the gastrointestinal tract. Third, the follow-up period was not sufficiently long. Finally, outcomes after CIEMR and EMR were analysed in this research, but ESD has been found feasible for the treatment of rectal carcinoid tumours in many studies [16,22-24]. In the future, we will compare ESD with CIEMR for the endoscopic treatment of rectal carcinoid tumours. 


\section{Conclusion}

In conclusion, CIEMR optimises the procedure of EMR and simplifies the technique of ESD. This method shows better histologically complete resection rate and more acceptable complication rate than EMR. CIEMR is a good alternative to EMR for en bloc resection of rectal carcinoid tumours less than $15 \mathrm{~mm}$ in diameter.

\section{Abbreviations}

EMR: endoscopic mucosal resection; CIEMR: endoscopic mucosal resection with circumferential incision; ESD: endsocopic submucosal dissection; $\mathrm{CT}$ : computer tomography; EUS: endoscopic ultrasonography; WHO: World Health Organization.

\section{Competing interest}

The authors declare that they have no competing interests.

\section{Authors' contributions}

$J H$ and ZSL contributed equally to this work. JH, ZSL and YSY designed the study; JH and ZSL drafted the manuscript. JY carried out analysis of histopathology. XDW, JYM, HD, and HBW carried out the cooperation of endoscopic operation. All the authors read and approved the final manuscript.

\section{Acknowledgements}

The authors earnestly thank Dr. Ming-zhou Guo, professors of Chinese PLA General Hospital, for providing some ideas for this study and for your sincere encouragement.

\section{Author details}

'Department of Gastroenterology, Chinese PLA 153 Central Hospital, 602 Zhengshang Road, Zhengzhou, Henan Province 450000, China. ${ }^{2}$ Department of Gastroenterology, Chinese PLA General Hospital, 28 Fuxing Road, Beijing 100853, China. ${ }^{3}$ Department of Pathology, Chinese PLA General Hospital, Beijing, China. ${ }^{4}$ Department of Gastroenterology, Chinese PLA General Hospital, Beijing, China.

Received: 12 September 2013 Accepted: 12 January 2014

Published: 28 January 2014

\section{References}

1. Maroun J, Kocha W, Kvols L, Bjarnason G, Chen E, Germond C, Hanna S, Poitras P, Rayson D, Reid R, Rivera J, Roy A, Shah A, Sideris L, Siu L, Wong R: Guidelines for the diagnosis and management of carcinoid tumours. Part 1: the gastrointestinal tract. A statement from a Canadian national carcinoid expert group. Curr Oncol 2006, 13:67-76.

2. Modlin IM, Lye KD, Kidd M: A five-decade analysis of 13,715 carcinoid tumors. Cancer 2003, 97:934-959.

3. Godwin JD 2nd: Carcinoid tumors. An analysis of 2,837 cases. Cancer 1975, 36:560-569.

4. Naunheim KS, Zeitels J, Kaplan EL, Sugimoto J, Shen KL, Lee CH, Straus FH 2nd: Rectal carcinoid tumors - treatment and prognosis. Surgery 1983, 94:670-676

5. Winburn GB: Multiple rectal carcinoids: a case report. Am Surg 1998, 64:1200-1203.

6. Schindl M, Niederle B, Häfner M, Teleky B, Längle F, Kaserer K, Schöfl R: Stage-dependent therapy of rectal carcinoid tumors. World J Surg 1998, 22:628-633. discussion 634

7. Soga J: Carcinoids of the rectum: an evaluation of 1,271 reported cases. Surg Today 1997, 27:112-119.

8. Mashimo Y, Matsuda T, Uraoka T, Saito Y, Sano Y, Fu K, Kozu T, Ono A, Fujii T, Saito D: Endoscopic submucosal resection with a ligation device is an effective and safe treatment for carcinoid tumors in the lower rectum. J Gastroenterol Hepatol 2008, 23:218-221.

9. Sohn DK, Han KS, Hong CW, Chang HJ, Jeong SY, Park JG: Selection of cap size in endoscopic submucosal resection with cap aspiration for rectal carcinoid tumors. J Laparoendosc Adv Surg Tech A 2008, 18:815-818.

10. Ichikawa J, Tanabe S, Koizumi W, Kida Y, Imaizumi H, Kida M, Saigenji K, Mitomi H: Endoscopic mucosal resection in the management of gastric carcinoid tumors. Endoscopy 2003, 35:203-206.
11. Kiesslich R, Neurath MF: Endoscopic mucosal resection: an evolving therapeutic strategy for non-polypoid colorectal neoplasia. Gut 2004, 53:1222-1224

12. Puli SR, Kakugawa Y, Gotoda T, Antillon D, Saito Y, Antillon MR: Meta-analysis and systematic review of colorectal endoscopic mucosal resection. World $J$ Gastroenterol 2009, 15:4273-4277.

13. Su MY, Hsu CM, Ho YP, Lien JM, Lin CJ, Chiu CT, Chen PC, Tung SY, Wu CS: Endoscopic mucosal resection for colonic non-polypoid neoplasms. Am J Gastroenterol 2005, 100:2174-2179.

14. Oda I, Saito D, Tada M, lishi H, Tanabe S, Oyama T, Doi T, Otani Y, Fujisaki لر, Ajioka Y, Hamada T, Inoue H, Gotoda T, Yoshida S: A multicenter retrospective study of endoscopic resection for early gastric cancer. Gastric Cancer 2006, 9:262-270.

15. Oka S, Tanaka S, Kaneko I, Mouri R, Hirata M, Kawamura T, Yoshihara M, Chayama K: Advantage of endoscopic submucosal dissection compared with EMR for early gastric cancer. Gastrointest Endosc 2006, 64:877-883.

16. Lee DS, Jeon SW, Park SY, Jung MK, Cho CM, Tak WY, Kweon YO, Kim SK: The feasibility of endoscopic submucosal dissection for rectal carcinoid tumors: comparison with endoscopic mucosal resection. Endoscopy 2010, 42:647-651.

17. Hirao M, Masuda K, Nakamura M: Endoscopic resection with local injection of HSE (ERHSE) in early gastric carcinomas. Gan No Rinsho 1986, 32:1180-1184.

18. Miyamoto S, Muto M, Hamamoto Y, Boku N, Ohtsu A, Baba S, Yoshida M, Ohkuwa M, Hosokawa K, Tajiri H, Yoshida S: A new technique for endoscopic mucosal resection with an insulated-tip electrosurgical knife improves the completeness of resection of intramucosal gastric neoplasms. Gastrointest Endosc 2002, 55:576-581.

19. Yamamoto H, Kawata H, Sunada K, Satoh K, Kaneko Y, Ido K, Sugano K: Success rate of curative endoscopic mucosal resection with circumferential mucosal incision assisted by submucosal injection of sodium hyaluronate. Gastrointest Endosc 2002, 56:507-512.

20. Kobayashi K, Katsumata T, Yoshizawa S, Sada M, Igarashi M, Saigenji K, Otani Y: Indications of endoscopic polypectomy for rectal carcinoid tumors and clinical usefulness of endoscopic ultrasonography. Dis Colon Rectum 2005, 48:285-291.

21. Jetmore AB, Ray JE, Gathright JB Jr, McMullen KM, Hicks TC, Timmcke AE: Rectal carcinoids: the most frequent carcinoid tumor. Dis Colon Rectum 1992, 35:717-725

22. Park HW, Byeon JS, Park YS, Yang DH, Yoon SM, Kim KJ, Ye BD, Myung SJ, Yang SK, Kim JH: Endoscopic submucosal dissection for treatment of rectal carcinoid tumors. Gastrointest Endosc 2010, 72:143-149.

23. Yamaguchi $N$, Isomoto $H$, Nishiyama $H$, Fukuda E, Ishii H, Nakamura T, Ohnita K, Hayashi T, Kohno S, Nakao K, Shikuwa S: Endoscopic submucosal dissection for rectal carcinoid tumors. Surg Endosc 2010, 24:504-508.

24. Zhou PH, Yao LQ, Xu MD, Chen WF, Zhong YS, Gao WD, He GJ, Qin XY: Endoscopic submucosal dissection for rectal carcinoid tumors. Zhonghua Wei Chang Wai Ke Za Zhi 2007, 10:319-322.

doi:10.1186/1477-7819-12-23

Cite this article as: Huang et al: Endoscopic mucosal resection with circumferential incision for treatment of rectal carcinoid tumours. World Journal of Surgical Oncology 2014 12:23

\section{Submit your next manuscript to BioMed Central and take full advantage of:}

- Convenient online submission

- Thorough peer review

- No space constraints or color figure charges

- Immediate publication on acceptance

- Inclusion in PubMed, CAS, Scopus and Google Scholar

- Research which is freely available for redistribution 